\title{
Controversies in Brain Death Declaration: Legal and Ethical Implications in the ICU
}

\author{
Sarang Biel, MD \\ Julia Durrant, $M D^{\star}$
}

\section{Address}

"Portland, OR, USA

(C) Springer Science+Business Media, LLC, part of Springer Nature 2020

This article is part of the Topical Collection on Critical Care Neurology

Keywords Brain death - Death by neurologic criteria $\cdot$ Harvard criteria $\cdot$ Uniform determination of death act $\cdot$ Religious accommodation

\begin{abstract}
Purpose of review This article provides a brief overview of the history and complexities of brain death determination. We examine a few legal cases that highlight some of the controversies surrounding the validity of brain death tests in light of varying state laws and institutional policy, the appropriateness of making religious accommodations, the dilemma of continuing organ-sustaining support in a pregnant brain-dead patient, and the issue of whether to obtain informed consent from surrogate decision makers before proceeding to testing.

Recent findings In response to physician concerns about navigating these complex cases, especially with laws that vary from state to state, the American Academy of Neurology has published a position statement in January of 2019 endorsing brain death as the irreversible loss of all functions of the entire brain. It provides positions on the determination of brain death as well as guidance surrounding requests for accommodation.

Summary Although death by neurologic criteria has been accepted as death medically for over 40 years, legal variance exists throughout the states, especially regarding religious accommodations and in pregnancy. Questions of whether to obtain informed consent from surrogate decision makers prior to brain death testing remain, and there is no guideline regarding obtaining ancillary testing. We expect to see continued cases that cause medical, legal, and ethical controversies in our ICUs. As such, uniform training in proper methodology in performing the brain death examination and appropriate use of ancillary testing is crucial, and there is a need for legal consistency in the acceptance of the medical standard.
\end{abstract}


Brain death, defined as the irreversible cessation of all brain activity, has been included in the medical and legal definition of death for nearly 40 years. Prior to the 1940s, the determination of death was defined by the cessation of blood circulation. In the 1950s, with the development of ventilators and cardiopulmonary resuscitation, death from circulatory stasis became "reversible" and physicians started treating patients in permanent comatose states, unable to be liberated from lifesupport machines [1-3]. In response, an ad hoc multidisciplinary committee of the Harvard Medical School was assembled to "define irreversible coma as a new criterion for death," and established medical criteria for the permanently nonfunctioning brain [4]. Use of the Harvard Criteria spread to hospitals across the country. As it was not legally binding, by the late 1970s, individual states had different criteria of death, and a patient could be legally dead in one state but alive in another [5]. To minimize conflict in these domains, in 1978, the US President's Commission for the Study of Ethical Problems in Medicine and Biomedical and Behavioral Research [6] sought input from medical and legal associations, as well several religious organizations, and established the Uniform Determination of Death Act (UDDA) of 1981, which included the determination of death by neurological criteria (DNC) as a legal equivalent to death by cessation of circulatory and respiratory functions [7]. All 50 states have since adopted the act, although specific language varies.

The advancement of medical technology and the ability to maintain metabolic and cellular homeostasis after neurological death have brought this scientific concept to the forefront of academic discussion. Public awareness and interest in brain death have also increased in the wake of legal cases that received widespread media coverage. A recent survey of adult and pediatric neurologists found that at least half have requests from family members to extend medical care to those who have met criteria for the diagnosis of brain death $[8,9]$. Only a few of these requests have led to legal proceedings [10], and when they have, court decisions have been contradictory. Many lawsuits have been withdrawn after circulatory demise of the patient, leaving legal questions unanswered. Divergent rulings in lawsuits between hospital systems and patient representatives have also contributed to legal uncertainty, translating to variations in state and institutional protocols, including clinical requirements, qualification and certification of examiners, apnea duration, and ancillary testing utilized. Independent of validated, scientific definitions, brain death has acquired social constructs with implications on public perception and expectations surrounding end-of-life care.

The aim of this article is to review the criteria for the diagnosis of brain and the specific examination requirements. We discuss some of the controversies surrounding brain death in the USA by examining five highprofile cases that best depict these themes: validity of brain death tests and protocols, state law differences, religious accommodation, consent for brain death testing from surrogate decision makers, and brain death in the pregnant patient. We also examine the effect of continued advances in medical technology (such as advanced cardiopulmonary support) and role of ancillary testing in testing protocols and highlight specific pediatric considerations. Finally, we outline suggestions for navigating the areas of controversy.

\section{Criteria for the diagnosis of brain death}

The diagnostic criteria for clinical diagnosis for brain death in adults was established by the Quality Standards Subcommittee of the American Academy of Neurology (AAN) in 1995 [11] and published in the guideline, "Determining brain death in adults." This evidencebased guideline is the foundation for the medical standards and requirements in determination of neurological death. It has since been updated in 2010 and again

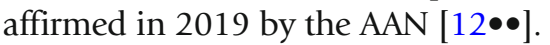

The clinical requirements and neurological examination for determination of brain death have not significantly changed from the initial criteria. Physicians must determine a neurological cause for the irreversible cessation of brain function and rule out confounders, as listed in Table 1. After determination of cause, two physicians perform a neurological exam, with careful evaluation of brain stem reflexes and response to stimulation. An apnea test is then performed, with the patient disconnected from mandated delivery of respirations from a ventilator, and the patient is closely monitored for respiratory efforts. Details of the reflex testing and the apnea test are described in Table 2. Depending on the age of the patient, the examination and apnea testing are repeated at set time periods. Ancillary tests, such as an electroencephalogram (EEG), digital subtraction cerebral angiogram, or radionuclide perfusion scintigraphy, 
are performed in patients unable to complete any part of the neurological examination or apnea testing. Death is declared once testing is completed.

A recent study by Braksick et al. examined individual practice variations in brain death examination across three separate institutions [14•]. Despite the vast majority of respondents reporting competency in performing brain death testing, only $25 \%$ reported conducting the testing in accordance with current practice guidelines. Ten percent of the providers did not perform an apnea test, the omission of which would be an incomplete (and incorrect) performance of brain death examination. Even more problematic, of the providers that obtained ancillary tests on an as-needed basis, more than a quarter ordered them if the patient breathed during apnea testing, a finding inconsistent with brain death. These survey results are troubling and suggestive that misdiagnosis of brain death may be more common than previously assumed.

In 2018, the AAN Ethics, Law, and Humanities Committee convened a multisociety summit to address these concerns and improve the public's trust and understanding of the concept of brain death [15]. Representatives from the American Academy of Pediatrics, American College of Radiology, American Neurological Association, American Society of Neuroradiology, Child Neurology Society, Neurocritical Care Society, and Society of Critical Care Medicine reaffirmed unanimously that brain death remains a valid and scientifically accepted concept and committed to standardization of training and institutional protocols by regulatory bodies. These goals were incorporated into the 2019 AAN position statement which called for "(1) uniform institutional policies for brain death determination within US medical facilities, (2) training programs for physicians who determine brain death, (3) credentialing mechanisms for physicians involved in brain death determination, regardless of specialty, (4) institutional policies that ensure compliance with the medical standards for brain death determination by physicians, (5) research that enhances the brain death knowledge base and the accuracy of its determination, and (6) enhanced professional and public education regarding these considerations" [12].

\section{Ancillary testing}

Per the AAN guidelines, confirmatory tests must be used in cases where components of the standard brain death examination cannot be performed or are inconclusive, such as facial trauma, incomplete apnea testing, and severe electrolyte or endocrine abnormalities [11]. Currently, the AAN considers EEG, nuclear scans, transcranial Doppler (TCD) ultrasonography, and cerebral angiography to be the preferred ancillary tests [16], which is also echoed in the American Academy of Pediatrics (AAP) guidelines [17]; beyond that, the societies do not offer uniform guidelines for the types of ancillary tests to be used, and current practice is largely determined by hospital protocol and personal preference [18 $\bullet$.

Ancillary tests such as angiography, TCD ultrasonography, and radionuclide perfusion scintigraphy are aimed at detection of cerebral blood flow; others such as EEG and somatosensory evoked potentials examine for evidence of cerebral activity [19]. CT and MR angiography and perfusion are more widely available than scintigraphy and are less invasive; however, both falsepositive and false-negative results have been described [16], and thus they are currently not recognized as acceptable ancillary tests by the AAN [19].

The sensitivity and specificity of each test varies widely and is subject to expertise in administration of the test as well as patient variables [20]. Tests, such as cerebral

Table 1. Elements to consider before proceeding to brain death examination [13]

- Identification of a clear etiology for brain dysfunction

- Exclusion of confounding conditions

a. Shock and/or systemic hypotension without stability on vasopressors

b. Hypothermia < 36 degrees Celsius

c. Drug intoxication

d. Sedating medication

e. Primary brain stem injury

f. Metabolic encephalopathies, including hypoglycemic, hepatic, uremic, and hyperosmolar encephalopathy

g. Electrolyte disturbances including hypophosphatemia, hypoglycemia, hyponatremia 
Table 2. Elements of the neurological criteria for the determination of death [13]

\begin{tabular}{|c|c|c|}
\hline Test & $\begin{array}{l}\text { Cranial } \\
\text { nerves } \\
\text { tested }\end{array}$ & Description and caveats \\
\hline Pupillary reflex & II, III & - Examine pupils for any change in response to bright light \\
\hline Corneal reflex & V, VII & - Examine blinking in response to light touch of the cornea \\
\hline $\begin{array}{l}\text { Oculocephalic reflex } \\
\text { (Doll's eye reflex) }\end{array}$ & III, VI, VI, VIII & $\begin{array}{l}\text { - Ensure cervical spine stability } \\
\text { - Examine for eye movement in response to turning of the head }\end{array}$ \\
\hline $\begin{array}{l}\text { Oculovestibular reflex } \\
\text { (Caloric reflex) }\end{array}$ & III, VI, VIII & $\begin{array}{l}\text { - Ensure intact tympanic membrane and no obstruction to external auditory canal } \\
\text { - Head of bed should be raised to } 45 \text { degrees } \\
\text { - Irrigate cold water }(\sim 50 \mathrm{~mL}) \text { into the ear } \\
\text { - Examine for any eye movement or nystagmus } \\
\text { - Allow } 5 \text { min between testing of each ear }\end{array}$ \\
\hline Cough & X, XI, XII & - Examine response by passing a suction catheter down the endotracheal tube \\
\hline Gag & IX, X & $\begin{array}{l}\text { - Examine for response to tactile stimulus to soft palate } \\
\text { - Movement of the endotracheal tube is discouraged, due to risk of vocal cord } \\
\text { damage or dislodgement of tube }\end{array}$ \\
\hline Apnea test & & $\begin{array}{l}\text { - Ensure hemodynamic stability, with normothermia } \\
\text { - Normalize pCO2 levels and preoxygenate with } 100 \% 02 \text { to avoid hypoxia } \\
\text { - Disconnect patient from the ventilator } \\
\text { - Monitor closely for any respiratory movement } \\
\text { - Any sign of respiratory movement indicates brain stem function } \\
\text { - After } 8-10 \text { min of apnea, obtain repeat } \mathrm{ABG} \text { and PaC02 level } \\
\text { - } 20 \mathrm{mmHg} \text { increase in PaCO2 is consistent with brain death } \\
\text { - If the rise of PaCO2 is lower than } 20 \mathrm{mmHg} \text {, the test is indeterminate. } \\
\text { Confirmatory testing should be considered } \\
\text { - If the patient develops any signs of hemodynamic instability including } \\
\text { hypotension, hypoxia, and arrhythmia, the test should be terminated }\end{array}$ \\
\hline
\end{tabular}

scintigraphy, may be limited by lack of availability in smaller hospital centers. Finally, patients with hemodynamic instability may not tolerate transportation out of the ICU for testing. Due to potential problems with all currently available ancillary tests, determination of death by neurologic criteria remains a clinical diagnosis, but requiring ancillary testing is gaining more support $[18 \bullet, 21 \bullet]$. Table 3 provides descriptions of the performance, interpretation, and limitations of various ancillary tests.

\section{Areas of controversy}

\section{Legal acceptance of neurological criteria}

While death by neurological criteria has been a legal definition of death in all fifty states since the implementation of the UDDA, the legitimacy of brain death determination has been questioned since initial implementation, especially following popular media reports of "brain dead" patients making recoveries. When updating the 2010 AAN guidelines, Wijdicks et al. found no peer-reviewed journal reports of patients who had regained neurological recovery after proper application of the AAN parameters [13]. In the decade since, case reports have been described of patients declared brain dead, who on further examination were noted to have some type of neurological function of uncertain origin [21]. Careful review of these case reports reveals incomplete and variable documentation of the confirmatory tests performed. Uncertainty of the proper application of AAN brain death guidelines makes retrospective interpretation of these cases impossible 


\section{Table 3. Ancillary testing for the determination of death}

Indications:

- Uncertainty in performing elements of the clinical exam

- Unable to test for brain stem reflexes (facial trauma, tympanic membrane perforation, etc.)

- Unable to complete apnea test

Test

Digital subtraction cerebral angiogram* [19]

\section{Brain radionuclide} imaging* [22]

Electroencephalogram* [23]

Transcranial dopplers* [24]

CT angiogram [25]

\section{Performance and interpretation}

- Inject contrast medium in the aortic arch under high pressure

- Contrast must reach both anterior and posterior circulations

Supports brain death:

- No intracerebral filling at the level of entry of the carotid or vertebral artery to the skull

- Patent external circulation

- Delayed filling of superior longitudinal sinus

- Injection of technetium radioisotope

- Static anteroposterior and lateral projection imaging of 500,000 counts at several time intervals: immediately, between 30 and $60 \mathrm{~min}$, and at $2 \mathrm{~h}$

- Can be performed in combination with single photon emission computed tomography to include axial images

Supports brain death:

- Hollow skull phenomenon: no radionuclide localization in the middle cerebral artery, anterior cerebral artery, or basilar artery territories of the cerebral hemispheres

- No tracer in superior sagittal sinus

- Placement of minimum of 8 scalp electrodes, distance at least $10 \mathrm{~cm}$ apart

- Sensitivity of at least $2 \mu \mathrm{V}$ in amplitude, interelectrode impedance below 10,000 ohms

Supports brain death:

- 30 min minimum of electrocerebral inactivity to intense somatosensory or audiovisual stimuli

- Bilateral insonation of intracranial and extracranial arteries

Supports brain death:

- Small early systolic peaks

- Lack of diastolic flow or reverberating flow

- Lack of forward flow

- Injection of intravenous contrast

- Arterial phase scanning about $20 \mathrm{~s}$ afterwards

- Venous phase scanning about $60 \mathrm{~s}$ afterwards to assess for delayed vascular opacification

Supports brain death:

- Lack of intracerebral vessel opacification, including cortical middle cerebral arteries and internal cerebral veins

\section{Caveats and limitations}

- Invasive procedure

- Transportation to angiography suite

- Image variability dependent on injection technique

- Use of nephrotoxic contrast material that may potentially impair graft function after organ transplantation

- Limited availability

- Transportation to radiology department

- Variable rate of radionuclide uptake across patients

- Subcortical structures not well-addressed

- Signal interference or contamination from surrounding ICU equipment

- High rate of diagnostic uncertainty $(20 \%)$ of cases due to inter and intra-rater variability

- Cannot be used in patient with craniectomies

- About $10 \%$ of patients have no acoustic windows

- No consensus agreement for specific criteria for brain death

- Use of nephrotoxic contrast material that may potentially impair graft function of kidneys harvested for transplant 
Table 3. (Continued)

\begin{tabular}{|c|c|c|}
\hline MR angiogram [26] & $\begin{array}{l}\text { Supports brain death: } \\
\text { - Widespread reductions in apparent } \\
\text { diffusion coefficient } \\
\text { - Loss of flow-void in intracranial internal } \\
\text { cerebral arteries }\end{array}$ & $\begin{array}{l}\text { - Time-consuming and therefore imprac- } \\
\text { tical for an unstable patient } \\
\text { - No consensus agreement for threshold } \\
\text { values consistent with brain death, } \\
\text { though various thresholds have been } \\
\text { proposed }\end{array}$ \\
\hline $\begin{array}{l}\text { Somatosensory } \\
\text { evoked potentials } \\
\text { (SSEP) [23] }\end{array}$ & $\begin{array}{l}\text { Supports brain death: } \\
\text { - Bilateral absence of N20-P22 response to } \\
\text { median nerve stimulation }\end{array}$ & $\begin{array}{l}\text { - Assess discrete pathways of brain, so } \\
\text { absence does not prove brain death } \\
\text { - Loss of SSEP can be seen in patients with } \\
\text { preserved cerebral blood flow (i.e., } \\
\text { post-anoxic cardiac arrest) }\end{array}$ \\
\hline $\begin{array}{l}\text { Brain tissue } \\
\text { oxygenation } \\
{[27,28]}\end{array}$ & $\begin{array}{l}\text { Supports brain death: } \\
\text { - Brain tissue oxygen tension }<5 \mathrm{mmHg}\end{array}$ & $\begin{array}{l}\text { - Probes sample only small region of } \\
\text { brain } \\
\text { prot enough patients to validate } \\
\text { procedure }\end{array}$ \\
\hline \multicolumn{3}{|c|}{$\begin{array}{l}\text { *American Academy of Neurology (AAN) identifies cerebral angiography (CA), cerebral scintigraphy, electroencephalography, and transcranial } \\
\text { Doppler ultrasonography as accepted ancillary tests } \\
\text { 1. Kramer AH. Ancillary testing in brain death. Semin Neurol. 2015;35(2):125-38. doi:https://doi.org/10.1055/s-0035-1,547,541 } \\
\text { 2. Joffe AR, Lequier L, Cave D. Specificity of Radionuclide Brain Blood Flow Testing in Brain Death: Case Report and Review. Journal of Intensive } \\
\text { Care Medicine. 2010;25(1):53-64. doi:https://doi.org/10.1177/0885066609355388 }\end{array}$} \\
\hline
\end{tabular}

[12]. In their 2019 position statement, the AAN reiterated that they were "not aware of any cases in which following these guidelines led to inaccurate determination of death with return of any brain function, including consciousness, brainstem reflexes, or breathing" [12].

Recently, the validity of the AAN brain death guidelines was questioned in the 2015 Supreme Court of Nevada case of Aden Hailu [29, 30], a 20-year-old who suffered intraoperative anoxic injury during an appendectomy. She was pronounced brain dead after she lost brainstem reflexes and showed no spontaneous respiration on apnea test. Her father filed a motion for a restraining order against the hospital from discontinuing organ support; the district court ruled against the motion, stating that Hailu met the AAN guidelines for brain death and was thus legally dead. The case was appealed to the Supreme Court of Nevada, who declared that the hospital had improperly determined Hailu as brain dead per Nevada statutes and reversed the lower court decision, holding that the district court had failed properly to consider whether the AAN Guidelines adequately measured all functions of the entire brain including the brain stem, and questioned whether the AAN Guidelines were considered accepted medical standards by the medical community. In response, the Nevada state legislature amended their state UDDA to require the declaration of neurological death (DND) follow guidelines established by the American Academy of Neurology or the Pediatric Section of the Society of Critical Care Medicine, including future updates [31]. This represents the first time state laws have stipulated the specific medical guidelines to be used in brain death declaration.

\section{Differences in state laws}

As highlighted by the lawsuit in Nevada, although all fifty states have adopted the UDDA recognizing neurological criteria for death, each state statute varies in their specific language and requirements [29•, 32•]. Some states such as Oklahoma require specific provisions in order to recognize brain death, such as attempts at cardiopulmonary resuscitation [33]. The state of Georgia includes civil/criminal immunity for people pronouncing death [34]. Other differences include specific qualifications of the types of practitioners allowed to pronounce death, whether it be physicians only or whether trained advanced practice providers be allowed; additionally, some states require that the physician declaring brain death be a specialist in neurology or similar field $[35,36]$. New Jersey is the only state that allows decla- 
ration of death solely on cardiorespiratory criteria if personal religious beliefs do not recognized brain death. There, a patient may not be declared dead legally even while meeting brain death criteria medically [37].

The differences in state law are well illustrated in the 2013 Jahi McMath case, a patient who was ruled to be legally dead in California but was treated as living under New Jersey law [38]. McMath was a 13-year-old who suffered anoxic brain injury from massive hemorrhage and cardiac arrest after a routine tonsillectomy at Children's Hospital Oakland. She was declared brain dead at the treating hospital on December 12, 2013. Her family petitioned to continue cardiopulmonary support, and ultimately the Alemeda County Superior Court ruled that she was legally dead. This decision was appealed to the United States District Court for the Northern District of California, with the eventual agreement that McMath's body with supportive equipment would be released to the custody of her mother. Her mother then transported McMath to a hospital in New Jersey, where she had a tracheostomy and percutaneous gastrostomy placed. In January 2018, when liver and kidney failure developed, ventilator support was removed, and a second death certificate was issued in the state of New Jersey. Since the McMath case, several lawsuits have arisen where families have sued to have the patient moved to New Jersey or other countries, such as Guatemala, where brain death criteria are not as strictly observed [39-42].

A recent survey of neurologists found that most physicians are unaware of the differences in state laws [8]. Identical laws for brain death declaration across all states could help ease some of the confusion surrounding and increase public acceptance of brain death. The AAN endorses development of uniform policies across states and institutions, with regulatory oversite by governing bodies to ensure proper training and credentialing of those making DNC declarations [12].

\section{Religious accommodation}

Many religious and cultural communities do not recognize death by neurological criteria, although ongoing debate over the interpretation, application, and adherence of practices and beliefs exists within these groups $[43,44]$. In many of these communities, death is defined solely as the irreversible cessation of heartbeat, which precludes the diagnosis of brain death. To some, withdrawal of cardiopulmonary support in this context may be viewed as akin to actively killing the patient [44]. While New Jersey is the only state to allow religious objection to the diagnosis of brain death, state provisions in California, New York, and Illinois require "reasonable accommodation" for religious beliefs [37, 4547] in institutional policies, but the circumstances and duration of accommodation is defined at the discretion of hospitals. In these states, patients are still considered legally dead when they meet brain death criteria, and accommodation surrounds the logistics of withdrawing cardiopulmonary support.

However, in the recent case of an Orthodox Jew who was declared brain dead, courts in New York have applied "reasonable accommodation" in a way that challenges the legal status of brain death as equivalent to cardiovascular death. In 2017, Yechezkel Nazar was admitted with a severe intracranial hemorrhage. Neurologic exam and CT findings were suggestive of brain death and accordingly, his physicians performed a neurological exam and apnea test on a holy day when the family was not able to be present. He was declared dead despite the expressed opposition of his family. His wife petitioned the court for nullification of the death certificate in order for medical insurance coverage to continue during the 3 weeks he remained on cardiopulmonary support before circulatory arrest. In early 2019, the death certificate was ruled null due to the hospital's lack of "reasonable accommodation" by not delaying the declaration of death until the family's concerns had been addressed. The court mandated a reissuance of the death certificate with the date of his circulatory arrest [48]. It remains to be seen how this ruling may affect other requests for religious accommodation.

The AAN's current position statement reiterates that brain death is a biological reality that is measured objectively; delaying declaration of death can lead to deleterious effects on patients and their families; and that physicians have both the authority and obligation to conduct examination for brain death as with circulatory death in a timely fashion [12]. Requests for short-term accommodation based on sincere social, moral, cultural, and religious beliefs should be respected; however, conditions and time frames should be explicitly addressed in institutional policies. The use of clergy, palliative care, ethics consultants, and administrative and legal officials in mediation with the family is encouraged; however, there is no ethical obligation in providing treatment to a dead patient. When supported by law and policies, and as a last resort, the AAN supports providers withdrawing organ-sustaining support despite the family's wishes [12]. 


\section{Consent for testing}

Much debate surrounds the question of whether informed consent should be obtained from surrogate decision makers before proceeding with brain death testing $[49,50]$. The AAN takes the position that informed consent for brain death testing should not be legally required, just as it is not required for determining circulatory death, but that surrogate decision makers should be informed of the process for brain death determination whenever possible [12].

The case of Allen Calloway from Montana illustrates some of the challenges surrounding consent during in the determination of brain death [51]. He was a 6-year-old who drowned and soon after admission to St. Vincent's Healthcare showed evidence of brain herniation. Two examinations separated by time are required in the determination of brain death in pediatrics [52]; Calloway's mother consented to the initial examination with results consistent with brain death but further testing was refused due to the parents' concern of stress and discomfort experienced by the patient. The County Court ultimately denied the hospital's request to proceed with further testing on the grounds that brain death testing counted as a "medical procedure," and that a parent has the sole authority to make medical decisions and consent to procedures on a child's behalf, based on the principle of personal autonomy.

Concurrently, a 2-year-old child, Mirranda Lawson, was admitted to Virginia Commonwealth University Medical Center after choking on a popcorn kernel, where her physicians determined that she was likely brain dead and attempted to perform apnea testing to determine death. Her parents declined the procedure and sought a temporary restraining order. The District Court sided with the hospital and confirmed that testing was necessary to make a determination of death and did not require consent from the parents [53]. Her parents appealed to the state Supreme Court; Lawson developed circulatory arrest before the hearing, leaving the lower court's order standing.

State laws surrounding consent to brain death testing are not uniform, as illustrated. Montana and Kansas prohibit brain death testing in the face of parental refusal. The state of Nevada explicitly amended its UDDA in 2017 to specify that brain death testing, including apnea testing, does not require consent [31].

\section{Brain death in pregnancy}

The medical, legal, and ethical complexities surrounding brain death increases with determination of brain death in pregnant patients, with additional considerations such as the determination of fetal viability, the risks and costs of continued maternal somatic support, and the dignity and autonomy of the pregnant patient or the surrogate decision maker balancing with the fetus's right to life [54]. Prolonged maternal somatic support requires exceedingly complex management of several medical conditions that arise with brain death, including hemodynamic instability, pituitary dysfunction, diabetes insipidus, neurogenic pulmonary edema, infection, and nutritional depletion. These complications and their management have an uncertain impact on fetal development $[55,56]$. While most states have not enacted laws that specifically address the brain dead pregnant patient, over 30 states have statutes that deny the withdrawal or withholding life-sustaining treatment from pregnant patients or invalidate legal advanced directives during pregnancy. Some require the continuation of support dependent on fetal viability and likelihood of survival [54]. At this time, only the states of Minnesota and Oklahoma have specific laws that require following the wishes of the pregnant patient or their proxy.

Inconsistency in the legal treatment of the brain dead pregnant patient is highlighted in the 2013 Texas case of Marlise Muñoz, who was 14 weeks pregnant when she was declared brain dead due to anoxia secondary to a pulmonary embolism [57]. The hospital continued cardiopulmonary support in accordance with state law that prohibits withdrawal of life-sustaining treatment from a pregnant patient, despite Muñoz's family's claim that Muñoz had previously expressed that she would not have wanted cardiopulmonary support. After 2 months, the court ruled that life-sustaining treatment only pertained to pregnant patients who were alive and ultimately ordered the withdrawal of support.

The AAN defers to the surrogate decision makers' wishes when considering organ-sustaining support in a brain-dead pregnant patient, granting accommodation to prolong use of organ-sustaining technology when requested, but also to uphold the surrogates' request to withdraw support particularly if fetus is not of viable gestational age or has sustained brain injury [12]. The American College of Obstetrics and Gynecologists Committee on Ethics released a statement in 2015 that the dignity and autonomy of the dying person should be respected regardless of pregnancy status and that technological support is ethical if the surrogate decision maker requests support for additional fetal development on the pregnant patient's behalf [58], a position 
reiterated by the International Federation of Gynecology and Obstetrics [59].

\section{New complexities in ICU care}

Advances in hemodynamic support have become invaluable tools in the treatment of severe pulmonary and cardiac diseases and have also created their own set of hurdles with brain death testing. The incidence of severe neurologic injury in patients on extracorporeal membrane oxygenation (ECMO) is reported to be as high as $50 \%[60,61]$, due to the inciting pathologies that led to initiating ECMO, the need for anticoagulation to prevent thrombosis in the ECMO circuit, and the coagulopathy and thrombocytopenia that develops as a result of platelet consumption due to the circuit [60]. Patients who require ECMO support may have significant cardiac or pulmonary disease burden and in these patients, apnea test may be too challenging to perform or they may be too hemodynamically unstable to transport to offsite locations for confirmatory testing [62-65].

A case from our institution illustrates this point. A patient was admitted to the cardiovascular ICU postoperatively on venoarterial extracorporeal membrane oxygenation (VA ECMO) support for management of cardiogenic and hemorrhagic shock. Despite a neurological exam consistent with severe and irreversible neurological injury, brain death testing was not considered, primarily due to uncertainty of how to perform testing. Heroic efforts continued for approximately 72 hours afterwards, when family decided to transition to comfort care and withdraw ECMO support.

There are no current guidelines or validated methods for performing the apnea test in these patients, and it is entirely omitted in some case reports [62]. Several aspects of ECMO pose challenges with regard to brain death testing [62]. Oxygenation $\left(\mathrm{O}_{2}\right)$ and removal of carbon dioxide $\left(\mathrm{CO}_{2}\right)$ is achieved by a countercurrent exchange system between the patient's blood and sweep flow through the circuit oxygenator. As such, changes in the blood flow or the sweep flow will affect a patient's $\mathrm{PaO}_{2}$ and $\mathrm{PaCO}_{2}$. Although sweep rates can be decreased to the lowest setting to achieve the rise in $\mathrm{PaCO}_{2}$ necessary to trigger a respiratory response, it risks causing a decrease in patient oxygenation and concomitant hemodynamic instability $[64,65]$. Some suggest adding $\mathrm{CO}_{2}$ via the ECMO blender to achieve a controlled rise in $\mathrm{PaCO}_{2}$ necessary to elicit respiratory response, which may have less hemodynamic effects $[62,63]$, but studies demonstrating the accuracy and effectiveness of these modifications are lacking.
Additionally, no guidelines exist for ECMO patients and ancillary testing despite some tests, such as a cerebral angiogram, having known limitations due to altered circulatory dynamics [66]. Careful consideration of other modalities, such as cerebral scintigraphy, will be necessary as more patients with various disease states are supported with ECMO and other highly invasive modalities.

\section{Pediatric considerations}

Guidelines for the process of determining brain death in the pediatric population were initially developed in 1987 by the AAP Task Force on Brain Death in Children [67]. It was revised in 2011 by a multidisciplinary committee from the AAP, Society of Critical Care Medicine, and Child Neurology Society to include updates in clinical information surrounding brain death in children and provide a biological rational for the use of age-based criteria in children [52]. Key portions of the process are largely similar to that of adults: confounding factors such as pharmacological agents must be absent, apnea testing must be performed in addition to a physical exam eliciting brain stem reflexes, and ancillary testing, though not required for the diagnosis, should be used in cases of uncertainty or difficulty in performing the brain death exam [52, 68, 69].

A few key differences remain in the requirements for brain death determination, specifically that two separate physicians must perform the exam with a period of time between the exams, depending on the age of the child. Infants over 37 weeks gestational age to 30 days require a waiting period of $24 \mathrm{~h}$, and children from 30 days to 18 years require $12 \mathrm{~h}$. There is insufficient clinical data in neonates under 37 weeks gestational age, as brainstem reflexes may not be fully developed [52, 68, 69].

A review of lawsuits regarding brain death from the last 50 years revealed that of the cases that listed the decedent's age, over half involved infants and children [70], and in a 2017 survey of pediatric neurologists and intensivists, more than half of the physicians reported being asked to continue organ support after the declaration of death [9]. The existence of multiple guidelines and the need for repeated tests on what is supposed to be an objective phenomenon may contribute to the perception of inconsistency and public confusion. Poor understanding and misinformed exposure to the concept of brain death make communication with families of brain dead children difficult; physicians report that requests for 
ongoing organ support most often stem from the belief that the patient could regain neurologic function [9]. Clear communication and education of family members regarding brain death and its determination is of utmost importance; a unified guideline between adult and pediatric populations while respecting physiological differences may be beneficial to that goal.

\section{Overcoming the controversies}

The AAN calls for the creation of standardized state or federal legislation, modeled after the Nevada statute, which specifically defers to current adult and pediatric brain death guidelines. It also calls for uniform policies in hospitals across the country to ensure compliance to brain death guidelines as a way to mitigate the differing legal interpretations and to emphasize to the public that "when these guidelines are followed, the result is an accurate determination of brain death" [71]. Proposals for a revised UDDA to be adopted by state legislatures have gained new traction [72].

In addition, educational institutions and hospitals across the country should implement programs to train and credential physicians on the criteria and guidelines for neurological determination of death. Given the relative infrequency of brain death determination, there is limited exposure to observe or perform brain death examination during training, with up to $27 \%$ of neurology residents reported to have finished their training without observing a single brain death examination in certain institutions [73]. Simulation training in brain death determination may be an ideal tool for education as it has been shown to increase trainee exposure to the process, provide opportunities for direct observation in a low stress environment, identify areas of focus and error, and improve assessed knowledge and subjective confidence in neurology and critical care trainees [73-75]. Other institutions have modified their policy to include a second brain death examination beyond the single exam, to allow more trainees to participate in the declaration, without adversely affecting organ donation rates or timing [76].

Medical students have also been proposed as an ideal educational target for brain death determination training. In an educational initiative which included a combined didactic and simulation session incorporating standardized trainers, a pretest and posttest comparison showed an improvement of background knowledge of brain death from 53 to $86 \%$. Subjective understanding and comfort performing the brain death evaluation and talking to families about brain death improved as well [77].

In an attempt to provide resources to both medical practitioners and the general public, the Neurocritical Care Society Brain Death Task Force has developed the Brain Death Toolkit as a multimedia educational tool [78]. It provides template checklists and policy statements for local adaptation, resources and articles in concordance with AAN guidelines, instructional videos surrounding various elements of the exam, and web-based modules for reference. A similar toolkit is provided from the AAP for pediatrics [79]. The Society has also recently launched an online certification course available in both English and Spanish, Brain Death Determination, which aims toward standardization of the credentialing of physicians by hospitals and institutions [80].

\section{Conclusion}

Beyond the bioethics involved in the determination of brain death in the face of organ donation and transplantation, the healthcare provider is faced with the ethics of stewardship in the setting of limited healthcare resources and its judicious utilization. While being sensitive and respectful toward various cultural and religious beliefs, there is no ethical obligation for continued cardiopulmonary support for a dead patient, and requests for indefinite continued support must be balanced against the moral distress of the healthcare team in delivering "futile care" as well as potential harm to other patients. 
The inconsistencies within personal and institutional practices in the medical field compounded with the differences in state legislatures' acceptance of the medical standard remain and form the base of many of the current medical, legal, and ethical controversies surrounding brain death as illustrated above. There is a need for uniformity in the definition and the objectivity in determining brain death, a need for consistency in the training and practice of carrying out brain death examination, and a need for invariability in the legal acceptance of the medical standard. In the face of continued advances in our technology and our ability to sustain cardiopulmonary function, cases of increasing complexity are expected to arise, and it is important to uphold the societal trust of our medical practice.

\section{Compliance with Ethical Standards}

\section{Conflict of Interest}

Sarang Biel and Julia Durrant declare that they have no conflict of interest.

Human and Animal Rights and Informed Consent

This article does not contain any studies with human or animal subjects performed by any of the authors.

\section{References and Recommended Reading}

Papers of particular interest, published recently, have been highlighted as:

- Of importance

$\bullet \quad$ Of major importance

1. Lofstedt S, Von Reis G. Intracranial lesions with abolished passage of X-ray contrast throughout the internal carotid arteries. Opuscula Medica. 1956;8:199-202.

2. Mollaret P. Le coma dépassé. Rev Neurol. 1959;1:5-15.

3. Wertheimer P, Jouvet M, Descotes J. A propos du diagnostic de la mort du systeme nerveux-dans les comas avec arret respiratoire traites par respiration artificielle. Presse Med. 1959;67(3):87-8.

4. A Definition of Irreversible Coma. JAMA. 1968;205(6):337. doi:https://doi.org/10.1001/jama. 1968.03140320031009 .

5. Truog RD, Pope TM, Jones DS. The 50-year legacy of the Harvard report on brain death. JAMA. 2018;320(4):335-6. https://doi.org/10.1001/jama. 2018.6990.

6. President's Commission for the Study of Ethical Problems in Medicine and Biomedical and Behavioral Research. Defining Death: A Report on the Medical, Legal and Ethical Issues in the Determination of Death. President's Council on Bioethics; 1981.
7. Guidelines for the Determination of Death. JAMA. 1981;246(19):2184. doi:https://doi.org/10.1001/ jama.1981.03320190042025.

8. Lewis A, Adams N, Varelas P, Greer D, Caplan A. Organ support after death by neurologic criteria: results of a survey of US neurologists. Neurology. 2016;87(8):827-34. https://doi.org/10.1212/wnl. 0000000000003008.

9. Lewis A, Adams N, Chopra A, Kirschen MP. Organ support after death by neurologic criteria in pediatric patients. Crit Care Med. 2017;45(9):e916-e24. https:// doi.org/10.1097/CCM.0000000000002452.

10. Lewis A. Contentious ethical and legal aspects of determination of brain death. Semin Neurol. 2018;38(5):576-82. https://doi.org/10.1055/s-00381668075 .

11. Wijdicks EFM. Determining brain death in adults. Neurology. 1995;45(5):1003-11. https://doi.org/10. 1212/wnl.45.5.1003.

12.• Russell JA, Epstein LG, Greer DM, Kirschen M, Rubin MA, Lewis A. Brain death, the determination of brain 
death, and member guidance for brain death accommodation requests: AAN position statement. Neurology. 2019. https://doi.org/10.1212/wnl.

0000000000006750.

This is the most recent position statement by the American Academy of Neurology that endorses that brain death is the irreversible loss of all functions of the entire brain, and that brain death is equivalent to circulatory death. It highlights the need for uniform policies surrounding brain death determination, and also provides recommendations and guidance surrounding requests for accommodation.

13. Wijdicks EFM, Varelas PN, Gronseth GS, Greer DM. Evidence-based guideline update: determining brain death in adults: report of the quality standards Subcommittee of the American Academy of neurology. Neurology. 2010;74(23):1911-8. https://doi.org/10. 1212/wnl.0b013e3181e242a8.

14. Braksick SA, Robinson CP, Gronseth GS, Hocker S, Wijdicks EFM, Rabinstein AA. Variability in reported physician practices for brain death determination. Neurology. 2019;92(9):e888-e94. https://doi.org/10. 1212/wnl.0000000000007009.

A study surveying physician variability in the training of brain death examination, in the practice of the components of the examination, and in the use of ancillary testing.

15. Lewis A, Bernat JL, Blosser S, Bonnie RJ, Epstein LG, Hutchins J, et al. An interdisciplinary response to contemporary concerns about brain death determination. Neurology. 2018;90(9):423-6. https://doi.org/10. 1212/wnl.0000000000005033.

16. Wijdicks EFM. The case against confirmatory tests for determining brain death in adults. Neurology. 2010;75(1):77-83. https://doi.org/10.1212/WNL. 0b013e3181e62194.

17. Guidelines for the Determination of Brain Death in Infants and Children: An Update of the 1987 Task Force Recommendations. 2011;128(3):e720-e40. doi:https://doi.org/10.1542/peds.2011-1511.

18. Robbins NM, Bernat JL. Practice current: when do you order ancillary tests to determine brain death? Neurol Clin Pract. 2018;8(3):266-74. https://doi.org/10. 1212/CPJ.0000000000000473.

Three case presentations highlighting some of the complexity in brain death determination.

19. Kramer AH. Ancillary testing in brain death. Semin Neurol. 2015;35(2):125-38. https://doi.org/10.1055/ s-0035-1547541.

20. Webb A, Samuels O. Brain death dilemmas and the use of ancillary testing. Continuum (Minneap Minn). 2012;18(3):659-68. https://doi.org/10.1212/01. CON.0000415434.91771.9b.

21. Dalle Ave AL, Bernat JL. Inconsistencies between the criterion and tests for brain death. J Intensive Care Med. 2018:0885066618784268. https://doi.org/10.1177/ 0885066618784268.

This article described several patients with inconclusive neurological exams following brain death declaration. It also advocates for universal utilization of ancillary testing in addition to neurological examination.
22. Joffe AR, Lequier L, Cave D. Specificity of radionuclide brain blood flow testing in brain death: case report and review. J Intensive Care Med. 2010;25(1):53-64. https://doi.org/10.1177/0885066609355388.

23. Welschehold S, Boor S, Reuland K, Thömke F, Kerz T, Reuland A, et al. Technical aids in the diagnosis of brain death. Deutsches Aerzteblatt Online. 2012. https://doi.org/10.3238/arztebl.2012.0624.

24. Chang JJ, Tsivgoulis G, Katsanos AH, Malkoff MD, Alexandrov AV. Diagnostic accuracy of Transcranial Doppler for brain death confirmation: systematic review and meta-analysis. Am J Neuroradiol. 2016;37(3):408-14. https://doi.org/10.3174/ajnr. a4548.

25. Garrett MP, Williamson RW, Bohl MA, Bird CR, Theodore N. Computed tomography angiography as a confirmatory test for the diagnosis of brain death. J Neurosurg. 2018;128(2):639-44. https://doi.org/10. 3171/2016.10.jns161042.

26. Goodson K, Lapointe M, Monroe T, Chalela JA. Intraventricular nicardipine for refractory cerebral vasospasm after subarachnoid hemorrhage. Neurocrit Care. 2008;8(2):247-52. doi:http://download.springer. com/static/pdf/568/art\%253A10.1007\%252Fs12028007-9017-z.pdf?auth66=1393459212 b237d695370d49e68ba75b83a03a8ddf\&ext=.pdf.

27. Palmer S, Bader MK. Brain Tissue Oxygenation in Brain Death. Neurocrit Care. 2005;2(1):017-22. https://doi. org/10.1385/ncc:2:1:017.

28. Smith ML, Counelis GJ, Maloney-Wilensky E, Stiefel MF, Donley K, Leroux PD. Brain tissue oxygen tension in clinical brain death: a case series. Neurol Res. 2007;29(7):755-9. https://doi.org/10.1179/ $016164107 \times 208121$.

29. Lewis A, Cahn-Fuller K, Caplan A. Shouldn't dead be dead?: the search for a uniform definition of death. J Law Med Ethics. 2017;45(1):112-28. https://doi.org/ $10.1177 / 1073110517703105$.

This paper provides a concise summary on the legal history of brain death determination and examines each state's legislative details surrounding brain death.

30. Hailu v Prime Healthcare. Second Judical District, Washoe County, Nevada; 2015.

31. Revises provisions governing the determination of death, (1 October 2017, 2017).

32. Nikas NT, Bordlee DC, Moreira M. Determination of death and the dead donor rule: a survey of the current Law on brain death. J Med Philos. 2016;41(3):237-56. https://doi.org/10.1093/jmp/jhw002.

This paper examines the dead donor rule and highlights variations across state statutes surrounding the determination of brain death. It emphasizes the importance of clarity and uniformity in legislation surrounding brain death with regards to medical ethics.

33. Uniform Determination of Death Act, State of Oklahoma, 63-3122 (2000).

34. Georgia Code Title 31. Health, 31-10-16 (2010).

35. Recognition of brain death under certain circumstances, State of Florida, 382.009 (2000). 
36. Uniform Determination of Death Act, State of Virginia, 54.1-2972 (2016).

37. New Jersey Declaration of Death Act, 26:6A (1991).

38. McMath v. California. District of Northern California; 2016.

39. Stinson v Children's Hospital LA. Adra L Pittman: Los Angeles Superior Court, California; 2016.

40. Jayden Auyeung v CHOP. Philadelphia Orphans Court Pennsylvania; 2018.

41. Banerjee v CHOP. Eastern District Court Pennslyvania; 2018.

42. Pierce v Loma Linda. San Bernardino County Superior Court, California; 2016.

43. Rosner F. Definition of death in Jewish law. N Y State J Med. 1983;83(7):973-8. doi:https://www.ncbi.nlm. nih.gov/pubmed/6577328.

44. Loike J, Gillick M, Mayer S, Prager K, Simon JR, Steinberg A, et al. The critical role of religion: caring for the dying patient from an orthodox Jewish perspective. J Palliat Med. 2010;13(10):1267-71. https://doi.org/ 10.1089/jpm.2010.0088.

45. California Health and Safety Code, State of California, 1254.4 (2008).

46. Illinois Anatomical Gift Act, 755 ILCS 50 (2004).

47. New York Codes, Rules, and Regulations, 400.16 (2011).

48. Nakar v NY Presbyterian Hospital. Kings County Supreme Court New York; 2019.

49. Lewis A, Greer D. POINT: should informed consent be required for apnea testing in patients with suspected brain death? No Chest. 2017;152(4):700-2. https:// doi.org/10.1016/j.chest.2017.05.030.

50. Truog RD, Tasker RC. COUNTERPOINT: should informed consent be required for apnea testing in patients with suspected brain death? Yes Chest. 2017;152(4):702-4. https://doi.org/10.1016/j.chest. 2017.05.032.

51. Allen Calloway. Montana ninth Judical District court; 2016.

52. Nakagawa TA, Ashwal S, Mathur M, Mysore M, Society of Critical Care Medicine ScoCCaSoNoAAoP, society $\mathrm{CN}$. Clinical report-guidelines for the determination of brain death in infants and children: an update of the 1987 task force recommendations. Pediatrics. 2011;128(3):e720-40. https://doi.org/10.1542/peds. 2011-1511.

53. Lawson v VCU Medical Center. Supreme Court of Virginia; 2016.

54. Varelas P, Greer D, Lewis A. Pregnancy and brain death: lack of guidance in U.S. hospital policies. Am J Perinatol. 2016;33(14):1382-7. https://doi.org/10. 1055/s-0036-1582445.

55. Esmaeilzadeh M, Dictus C, Kayvanpour E, SedaghatHamedani F, Eichbaum M, Hofer S, et al. One life ends, another begins: management of a brain-dead pregnant mother-a systematic review. BMC Med. 2010;8:74. https://doi.org/10.1186/1741-7015-8-74.

56. Burkle CM, Tessmer-Tuck J, Wijdicks EF. Medical, legal, and ethical challenges associated with pregnancy and catastrophic brain injury. Int J Gynecol Obstet. 2015;129(3):276-80. https://doi.org/10.1016/j.ijgo. 2014.12.011.

57. Munoz v. JPS Hospital. District Court, Tarrant County, Texas; 2014.

58. American College of Obstetrics and Gynecology. Committee Opinion No. 617: end-of-life decision making. Obstet Gynecol. 2015;125(1):261-7. https:// doi.org/10.1097/01.Aog.0000459869.98866.91.

59. Dickens B. Brain death and pregnancy. Int J Gynecol Obstet. 2011;115(1):84-5. https://doi.org/10.1016/j. ijgo.2011.07.002.

60. Mateen FJ, Muralidharan R, Shinohara RT, Parisi JE, Schears GJ, Wijdicks EF. Neurological injury in adults treated with extracorporeal membrane oxygenation. Arch Neurol. 2011;68(12):1543-9. https://doi.org/10. 1001/archneurol.2011.209.

61. Barrett CS, Bratton SL, Salvin JW, Laussen PC, Rycus PT, Thiagarajan RR. Neurological injury after extracorporeal membrane oxygenation use to aid pediatric cardiopulmonary resuscitation. Pediatr Crit Care Med. 2009;10(4):445-51. https://doi.org/10.1097/PCC. ob013e318198bd85.

62. Muralidharan R, Mateen FJ, Shinohara RT, Schears GJ, Wijdicks EF. The challenges with brain death determination in adult patients on extracorporeal membrane oxygenation. Neurocrit Care. 2011;14(3):423-6. https://doi.org/10.1007/s12028-011-9516-9.

63. Beam WB, Scott PD, Wijdicks EFM. The physiology of the apnea test for brain death determination in ECMO: arguments for blending carbon dioxide. Neurocrit Care. 2019;31:567-72. https://doi.org/10.1007/ s12028-019-00784-7.

64. Bein T, Muller T, Citerio G. Determination of brain death under extracorporeal life support. Intensive Care Med. 2019;45(3):364-6. https://doi.org/10.1007/ s00134-018-05510-z.

65. Jarrah RJ, Ajizian SJ, Agarwal S, Copus SC, Nakagawa TA. Developing a standard method for apnea testing in the determination of brain death for patients on venoarterial extracorporeal membrane oxygenation: a pediatric case series. Pediatr Crit Care Med. 2014;15(2):e38-43. https://doi.org/10.1097/PCC. 0000000000000006.

66. Acharya J, Rajamohan AG, Skalski MR, Law M, Kim P, Gibbs W. CT angiography of the head in extracorporeal membrane oxygenation. AJNR Am J Neuroradiol. 2017;38(4):773-6. https://doi.org/10.3174/ajnr. A5060.

67. Guidelines for the determination of brain death in children. Task Force for the determination of brain death in children. Neurology. 1987;37(6):1077-8. doi:https://doi.org/10.1212/wnl.37.6.1077.

68. Mathur M, Ashwal S. Pediatric brain death determination. Semin Neurol. 2015;35(2):116-24. https://doi. org/10.1055/s-0035-1547540.

69. Martin SD, Porter MB. Performing the brain death examination and the declaration of pediatric brain 
death. J Pediatr Intens Care. 2017;6(4):229-33. https://doi.org/10.1055/s-0037-1604013.

70. Lewis A, Scheyer O. Legal objections to use of neurologic criteria to declare death in the United States: 1968 to 2017. Chest. 2019;155(6):1234-45. https://doi.org/ 10.1016/j.chest.2019.03.018

71. American Academy of Neurology. AAN Calls for Uniformity of Brain Death Determination [Press Release]. 2019.

72. Lewis A, Bonnie RJ, Pope T. It's time to revise the uniform determination of death Act. Ann Intern Med. 2019. https://doi.org/10.7326/m19-2731.

73. Hocker S, Schumacher D, Mandrekar J, Wijdicks EFM. Testing confounders in brain death determination: a new simulation model. Neurocrit Care. 2015;23(3):401-8. https://doi.org/10.1007/s12028015-0130-0.

74. Hocker S, Wijdicks E. A future for simulation in acute neurology. Semin Neurol. 2018;38(04):465-70. https://doi.org/10.1055/s-0038-1666986.

75. Hocker SW, Eelco. Simulation in Acute Neurology. Elsevier; 2018

76. Kashkoush A, Weisgerber A, Dharaneeswaran K, Agarwal N, Shutter L. Medical training and the brain death exam: a single Institution's experience. World
Neurosurg. 2017;108:374-8. https://doi.org/10.1016/ j.wneu.2017.08.185.

77. Lewis A, Howard J, Watsula-Morley A, Gillespie C. An educational initiative to improve medical student awareness about brain death. Clin Neurol Neurosurg. 2018;167:99-105. https://doi.org/10.1016/j.clineuro. 2018.01.036.

78. Neurocritical Care Society. Brain Death Toolkit. 2014. https://www.pathlms.com/ncs-ondemand/courses/ 1223.

79. American Academy of Pediatrics. Guidelines for Brain Death in Children: Toolkit. https://www.aap.org/enus/Documents/socc_pediatric_bd_guideline_tool.pdf. 80. Neurocritical Care Society. Brain Death Determination: standardizing the process of brain death diagnosis through online credentialing. 2019. https://www. pathlms.com/ncs-ondemand/courses/13808.

\section{Publisher's Note}

Springer Nature remains neutral with regard to jurisdictional claims in published maps and institutional affiliations. 